Comparative Philosophy Volume 7, No. 1 (2016): 1-19

Open Access / ISSN 2151-6014

www.comparativephilosophy.org

\title{
THE SOCIAL NATURE OF INDIVIDUAL SELF-IDENTITY: AKAN AND NARRATIVE CONCEPTIONS OF PERSONHOOD
}

\author{
COREY L. BARNES
}

\begin{abstract}
Marya Schechtman has given us reasons to think that there are different questions that compose personal identity. On the one hand, there is the question of reidentification, which concerns what makes a person the same person through different time-slices. On the other hand, there is the question of characterization, which concerns the actions, experiences, beliefs, values, desires, character traits, etc. that we take to be attributable to a person over time. While leaving the former question for another work, Schechtman answers the latter question by proposing what she terms the narrative selfconstitution view, whereby Schechtman claims that we account for intuitive features (moral responsibility, survival, compensation, and self-interested concern) of characterization through narratives. Still, merely having a narrative is not enough. In order to live the life of a person, an agent's narrative must sync with the narrative told about him/her in community. This paper, while in full agreement with Schechtman's claim regarding narratives and their ability to explain the intuitive features that regard the question of characterization, puts pressure on the latter claim. I argue that a person's narrative is not merely one that synchs with the narrative told in community, but one that is determined by the person's community. In focusing on Schechtman's second claim, I appeal to the Akan conception of personhood, showing that the community sets the parameters of personal identity, and by body politics and conferring social recognition, determines the traits that we take to be attributed to a given person over time.
\end{abstract}

Keywords: personal identity, Akan conception of personhood, comparative philosophy

Marya Schechtman has given us a very rich conception of the self that she takes to answer a fundamental question of personal identity, namely how an individual can be categorized as the same person, as opposed to the question regarding what makes a person the same persisting or perduring person at different times. According to Schechtman this question, termed the characterization question, asks "which actions, experiences, beliefs, values, desires, character traits, and so on... are to be attributed to a given person" (Schechtman 1996, 73) Schechtman answers this question by

BARNES, COREY L.: Department of Philosophy, The University of Memphis, USA. Email: clbrnes1@memphis.edu 
arguing that "a person creates his [or her] identity by forming an autobiographical narrative - a story of his [or her] life" (Schechtman 1996, 93). One of the biggest reasons why this conception is so rich is because it accounts for the social nature of personal identity. She tells us that "an individual's self-narrative must conform in certain crucial respects to the narrative others tell of his [or her] life" (Schechtman 1996, 93). In short, Schechtman tells us that an individual's narrative must synch-up with the community's narrative about the individual. Still, it appears to me that Schechtman's idea does not go far enough in reporting the social nature of individual identity. Schechtman's theory promotes a narrative identity constructed by the person whose life is narrated, without being either directed or determined, which is to say strongly influenced, by his/her community (Schechtman 1996, 111). In so doing, I believe that Schechtman's view misses the strength of how communities are responsible for the parameters that our identities take and how much weight communities have on our self-images, such that forming identities is impossible without communities directing and determining the types of identities formed. In short, Schechtman's view falls short of appreciating how communities are responsible for our ability to be categorized as the same person.

In this paper I would like to elucidate Schechtman's view, raising questions about it insofar as it lacks a full appreciation for the social nature of personal identity. In so doing, I would like to introduce a conception of personhood that receives very little attention in debates on personal identity in western philosophy, namely the Akan conception of personhood. In introducing this conception, I look at two Ghanaianborn thinkers, Kwame Gyekye and Kwasi Wiredu, both of whom have written extensively on the Akan conception of personhood. Using Wiredu's account, I argue that the Akan conception of personhood shows us the full weight that our communities have on shaping our identities. The fundamental question guiding this work is: what does our communities have to do with how we are categorized? Ultimately, what I argue is that who we are, which is to say how we are categorized (to use Schechtman's division), is more strongly connected with our communities than Schechtman's view reports. I would now like to begin with an elucidation of Schechtman's view.

\section{THE NARRATIVE SELF-CONSTITUTION VIEW}

Schechtman employs her narrative theory in order to "explain our intuitions about the relation between personal identity and survival, moral responsibility, self-interested concern, and compensation" that cannot be explained by either reductionist psychological continuity theories or reductionist bodily continuity theories (Schechtman 1996, 1). Schechtman thinks that people have strongly held ordinary opinions about these "four features" of characterization in relation to personal identity, and thus that they must be taken into account by complete explanations of personal identity. On Schechtman's view, both sets of reductionist theories fail insofar as they attempt to answer the question of how persons should be categorized as the same person by answering how persons reidentify as the same person. For 
example, reductionist reidentification theorists will answer the question about when someone is moral responsibility for some action by asserting that a person is morally responsible for some action that occurred at $t_{1}$ only if he/she is identical in the present (at $t_{2}$ ) with that person who performed the action at $t_{1}$. However, "these 'reidentification theorists' fail to appreciate the boundaries of this [reidentification] question" (Schechtman 1996, 2). Questions about characterization and those of reidentification are thought to be answerable by the same theory. "As a result considerations linked to the categorization question creep into their investigation and are used (inappropriately) to guide their formulation of reidentification criteria, which undermines their project...at its very foundations" (Schechtman 1996, 2). These theorists mistakenly think that their theories will account for the four features as reidentification theories because their theories purport to define identity and because identity is linked to the four features. Essentially, these theorists fail to recognize that the issues and questions of personal identity are not monolithic; there are two different issues at play in personal identity, namely the issue of what is necessary to have the same person at two time-slices and the issue of the four features. The former relates to the reidentification question, while the latter relates to the categorization question. On Schechtman's view, answering one question will not address issues relating to the other question. ${ }^{1}$

Now, Schechtman thinks that the two sets of reductionist theories fail to account for the four features in different ways. Schechtman thinks that even though theories concerning the continuity of bodies purport to answer the reidentification question, it as counterintuitive to think that bodily continuity theories account for the four features (Schechtman 1996, 67). Schechtman tells us that it seems intuitive to think that bodily continuity tells us something about identity, insofar as: "Evidence that the present human body is the same as the past one is thus implicitly accepted as evidence that the present person is the same as the past one" (Schechtman 1996, 13). However, in addition to concerns about what accounts for the continuation of our bodies into future times, we have practical concerns that a psychological theory appears more suitable to account for. So, let's take two individuals, Maria and Jane, and let us say that Maria performed some task for which she is to be compensated. Now, let us say that the day before Maria is to be compensated her psyche is placed into Jane's body and Jane's psyche into Maria's body. Schechtman thinks that we would intuitively think that the body with Maria's psyche should be the one that is compensated for performing the task, not the body that actually performed the task. Thus, in Schechtman's view, we intuitively think that psychological continuity theories are better equipped to account for the four features.

Though it might appear that psychological continuity theories are better equipped to account for the four features, Schechtman thinks that they fail to account for the four features. Schechtman reasons that they are "unable to explain the importance we attach to identity..." (Schechtman 1996, 52). Schechtman terms this failure the

\footnotetext{
${ }^{1}$ It is important to note that Schechtman is not committed to the view that the two questions are unrelated. Schechtman provides evidence for this note on page 68 of The Constitution of Selves.
} 
"extreme claim." The first premise of the extreme claim is that "the four features require numerical identity - qualitative similarity will not hold" (Schechtman 1996, 52). What Schechtman has in mind here is that the four features must refer to the same person from the past to the future, and not a future person who is similar to the person of the past. The second premise of the extreme claim states that "the psychological continuity theory collapses the distinction between someone being me and someone being like me - that all identity amounts to on this view is psychological similarity between distinct individuals" (Schechtman 1996, 53). Schechtman thinks that psychological continuity theories can only account for personal identity by relational parts that are both temporary and distinct, such that a person at one time $\left(\mathrm{t}_{1}\right)$ is only like (because he/she is in some way distinct from) a person at another time $\left(t_{2}\right)$. Psychological continuity theorists cannot produce a theory that allows for the numerical identity of a person at $t_{1}$ and $t_{2}$, only a qualitative similarity between the two. The conclusion of the extreme claim follows naturally from these two premises:

If the relation of qualitative similarity between the psychological lives of distinct individuals is insufficient to underlie the four features, and if the psychological continuity theory provides a definition of identity according to which all it is for some future person to be me is for that person to have a psychological life qualitatively like mine, then the psychological continuity theory obviously fails to account for the importance of identity (Schechtman 1996, 54).

How this fails to account for the importance that we attach to identity is that we all think it is the same person who must be compensated or held morally responsible for some action; it is the same self that we are concerned about; and it is the same self that we think must survive when we talk about personal identity. Why would someone be responsible for the action of someone who he/she is like? Or, why would someone be concerned (in the way that we are concerned with ourselves) for someone that he/she is merely like? As such, Schechtman thinks it fitting to conclude that both bodily and psychological continuity theories that purport to answer the reidentification question are insufficient to account for our intuitions about these four features, which are largely what makes the question of personal identity relevant, and which are accounted for by answering a question that is different in nature - namely the characterization question.

As stated in the introduction, the characterization question asks which "actions, experiences, beliefs, values, desires, character traits, and so on... are to be attributed to a given person" (Schechtman 1996, 73). The theorist who attempts to answer the characterization question gives an account of "which characteristics are truly those of some person..." (Schechtman 1996, 73). The characterization question is markedly different from the reidentification question insofar as the latter involves a logical relation of identity (or similitude in the case of what these theories are actually able to accomplish) in some person over time, while the former asks what psychical properties most characterize some person over time. Schechtman thinks that the four features can be accounted for when we engage the former question, and her answer to 
the former question is that we should think of personal identity in terms of a narrative. Schechtman titles this view the narrative self-constitution view.

For Schechtman, personal identity is intimately linked to situating biological movements in a context that makes bodily movements more than simply mechanical or biological responses - they are actions. These actions take on a particular linear organization, or more explicitly a narrative. When I act, I take myself to be the experiencing subject, which is to say that I take myself to be an agent. Schechtman tells us that: "Perhaps the most salient feature of narrative form in general is that the individual incidents and episodes in a narrative take their meaning from the broader context of the story in which they occur" (Schechtman 1996, 96). It is only insofar as the movements (incidents and episodes) occur in the context of a narrative that they become meaningful. Thus, in order to explain an episode such as me reaching for a bottle of water, it must be understood that I am thirsty; and, in order to explain my being thirsty, it must be understood that I have just run five miles. Present episodes of experience are explained by past episodes.

Episodes of experience that get organized into a narrative are not merely explained by past episodes, but project into the future. What this means is that current episodes of experience are also explained by anticipated episodes. For example, I stated that in order to explain the bottle-reaching episode one must understand the context in which the bottle-reaching episode occurred, namely my being thirsty, and that my being thirsty is situated in the context of my having just run five miles. Now, one might say that in order to explain the five mile-running episode one needs to understand that I desire and anticipate winning a gold medal in the Olympic Games as a successful track-and-field star. Thus, I not only understand my past actions in a particular context, but I extend my narrative to anticipated future occurrences. In short, the narrative, as a set of linearly organized episodes, is not closed. Thus, Schechtman tells us that: "At the core of this view is the assertion that individuals constitute themselves as persons by coming to think of themselves as persisting subjects who have had experiences in the past and will continue to have experiences in the future, taking certain experiences as theirs. Some, but not all, individuals weave stories of their lives, and it is their doing so which makes them persons" (Schechtman 1996, 94).

The particular content of an agent's narrative is what constitutes the characterization portion of personal identity. And with regard to this content, nothing that I conceptualize as a part of the content that makes up my identity occurs apart from the context of $m y$ story or narrative. When I speak about my life as a narrative, I am not speaking about episodes disconnected from my narrative. Thus, an event such as walking to the grocery store must refer to prior and future anticipated episodes as contexts in order to be conceptualized as occurring in my narrative. And when we speak about my self-conception as a narrative, we cannot be referring to episodes in isolation or detached from it.

One must take care to notice how this theory provides an account of the four features. For the sake of time, let us look at compensation and self-interested concern. Beginning with the latter, we can acknowledge that "what makes a particular 
anticipation of the future a part of someone's narrative is precisely the influence it has on the character of his present experience" (Schechtman 1996, 154-155). My desire to win a gold metal at the Olympic Games is a concern that has a direct bearing on my present psychological state. I worry about my future self, get excited in the present because of the anticipated future experiences and successes, and it is this worry and excitement - this concern - that motivates present action. Now certainly it is not simply this event that gives me worries and excitement, but the entirety of my future that I am concerned with, insofar as the Olympic games are not the only things in the future that concern me. By the time that I am concerned about this event in my narrative, there are innumerable anticipated events pressing me, such that I am concerned about the quality of my future as a whole, and not simply the individual future (and present) events that shape my present psychological state.

"The concept of compensation is closely tied to that of self-interested concern-it is because we care about what our futures will be like that the promise of forthcoming benefits can make up for present difficulties" (Schechtman 1996, 157). Schechtman's theory is able to account for compensation (like self-interested concern) because it is able to explain present psychological states by appeal to future anticipations and rewards (or fears). These future states explain who we are, and thus this theory about who we are naturally accounts for them.

What has just been discussed refers to one major element of Schechtman's theory, namely that individuals become persons by creating narratives. I am in complete agreement with this element of Schechtman's theory. "The Second [major element] is a set of limitations on the form of an identity-constituting narrative" (Schechtman 1996, 95). In order to understand Schechtman's narrative view, we cannot simply think it divorced from one's community. In fact, I think that this is one of the most impressive aspects of the theory. Schechtman tells us that: "A view that held that any narrative self-conception was identity-constituting would be committed to the obviously false claim that persons cannot be mistaken about themselves" (Schechtman 1996, 94). There are particular constraints on a narrative that a person can have. One of these constraints is that the person's narrative must match the narrative of the person that is told by his/her community; the two narratives must be in synch. Thus, I cannot construct a narrative as a rich and famous professional athlete when I am a mere gas-station attendant. My community must be able to affirm the narrative that I take to be mine. Schechtman's essential argument, as it relates to the social nature of personal identity, is that a person's narrative must be in synch with his/her community's understanding of his/her narrative because he/she must be able to live a life of a person. The life of a person necessarily includes social interactions and engagements, moral expectations, and future planning, which Schechtman thinks possible only if the community and the narrator have the same (or very similar) conceptions of the person's experiences. If I attempt to narrate my life as a rich and famous professional athlete when my community understands my narrative to be a gas-station attendant's, then I must do so in isolation from my community, particularly when I can only live this life by commanding the respect, signing the contracts, and being compensated as a professional athlete. Insofar as it 
takes engagements with a community to do these things as a person would, my community must also understand my narrative to be that of a rich and famous professional athlete. This synching is necessary if I am to live among them. Living a social life, or the life of a person, depends on the synchronization of the narrative of the individual who identifies personally with the narrative of his/her social community. As such, a person cannot adopt any narrative or any self-concept.

Thus, Schechtman gives us two basic sets of intuitions that lead to the narrative self-constitution view. She tells us "first that in order to be a person one needs a particular kind of subjectivity and orientation towards one's life, and second, that in order to be a person one's self-conception must cohere with what might be called the 'objective' account of her life-roughly the story that those around her would tell" (Schechtman 1996, 95). Still, one might think that there is a deeper connection between these two sets of intuitions. One might ask how the community that one's narrative must synch up with confines, sets the parameters for, and ultimately defines the possibilities of the narrative that one is able to take. Let us say that we have a person who is very much committed to gender equality. From where did this commitment derive? What social structures must be present in order for one to have a narrative that accords to any particular narrative? Further, what is the role of the body in the process of narrative-construction? If we say that the particular body of a person plays a role in the narrative that he/she constructs, and we affirm that a community's politics places a value upon that body, then we must affirm that the community's valuation of the body affects the narrative that that person can/will construct. For example, what happens when one's body is colored or gendered? How does bodypolitics affect narrative-construction? Still further, what affect does a community have on a person's motivations to construct their identities in certain sorts of ways?

Given these questions, I argue that Schechtman does not go far enough in elucidating the social nature of the characterization portion of personal identity. I question whether there might be more than simply a synchronization of a person's narrative and the narrative told about the person by his/her community. In what follows I argue that a person's narrative is not merely one that must be in synch with the one told in community, but also one that is determined by the community. By appealing to the Akan conception of personhood, I show that the community sets the parameters of personal identity, and by body-politics and social recognition, the community determines what characteristics a person can/will take.

\section{THE AKAN CONCEPTION OF PERSONHOOD}

The Akan conception of personhood is a very complicated and contentious conception that is far from settled among philosophers. Insofar as I do not want to leave the reader with the idea that there is a singular understanding of the conception, I would like to elucidate the Akan conception of personhood through two Ghanaian philosophers, Kwame Gyekye and Kwasi Wiredu. Both Gyekye and Wiredu have radically different views on the Akan conception of personhood. My argument is that if we take Wiredu's understanding seriously, then we can begin to more fully 
appreciate the social nature of personal identity insofar as it relates to the categorization question. As such, I will elucidate the Akan conception of the human being, which is a composite of three essential elements. Afterwards, I will introduce Wiredu's argument that personhood is to be understood separately from humanity as an achievement in community that human beings strive towards. For completeness, I will follow this introduction with a brief illustration of Gyekye's response to this argument, and then Wiredu's rejoinder to Gyekye. This will lead me to my ultimate goal, which is to illustrate just how looking at personal identity through the Akan gives us a deeper appreciation of the social nature of personal identity as it relates to the characterization question.

With regard to the human being, both thinkers agree that for the Akan the human being is composed of three principle parts, ōkra (which can be understood as the lifespark of a living organism, or that which answers why one thing is alive and another thing is not), sunsum (the character, or "that which is responsible for the unique personal presence that an individual has") (Wiredu 1992a, 112), and honam (the body of the organism). While Gyekye largely remains silent on the divisions of the honam, Wiredu points out that the honam is in part composed of the mogya (blood). For Wiredu, the mogya plays a key role in conveying the social nature of the human, even apart from the particular conception of personhood that Wiredu attributes to the Akan. As stated, these understandings diverge quite a bit. Still, engaging both thinkers' understandings will give a richer notion of each conception.

For Wiredu and Gyekye, the ókra is what is thought to be the life-spark of the human being. Both thinkers take the $\bar{o} k r a$ to be an essential part of the human being that functions (among other things) to explain the difference between living and nonliving beings. Still, for both thinkers the term unfolds in different ways, which is to say that Wiredu and Gyekye differ on the ontology of the ōkra. Gyekye models the $\bar{o} k r a$ on Western conceptions of the soul, while Wiredu cautions us not to link the $\bar{o} k r a$ too closely with Western conceptions, insofar as Western conceptions of the soul (on Wiredu's account) tend to be loaded with components such as the mind, character, and immateriality.

With regard to the okra, Wiredu tells us that: "There is, most visibly, the assemblage of flesh and bones that form the body. But, reason the Akans, something must make the difference between a dead, inert body, and a living one. This they attribute to an entity called okra, which they consider an actual particle of the supreme being" (Wiredu 1997, 48). At first blush, this sounds a bit like Aristotle, who argued that the soul, which one might take to be closest to the Akan conception of $\bar{o} k r a$, is the first-principle of a natural body that has life potentially (Aristotle On the Soul, Book II, 412a). Yet, one can see the connection between ōkra and some divinity or supernatural being or substance. Whereas Aristotle could explain the principle that separates a living body from a dead or homonymous body by appeal to nature, the Akan, on Wiredu's reading, seem to understand the principle as essentially connected to divinity. Further, Aristotle seems to promote the idea that thought is a function of the human soul, perhaps making the soul more than just a "principle" that explains the living-state of a particular being with a particular constitution (Aristotle On the 
Soul, Book III, 427a-435b). For the Akan, okra is not the housing-place of the adwene, which Wiredu takes to be a capacity for some body to think thoughts, feel emotions, etc. (Wiredu 1997, 48).

Now, for Wiredu, the $\overline{o k r a}$ is what grounds the basic equality of all human beings. Wiredu tells us that: "In virtue of that element [the $\overline{o r a}$ ], absolutely everyone, regardless of race, gender, or achievement is entitled to a certain degree of respect and consideration" (Wiredu 1992a, 112). And because such a spark is divine, it seems to promote the idea that humans are superior to other living things. Still, one may wonder whether the term is meant to explain the distinction between living and nonliving things, or merely a particular spark that separates human life from all other living things? Both Wiredu and Gyekye seem to equivocate on this point. Both theorists seem to offer an explanation of the term insofar as it answers the question, "why is X alive?" Still, both seem to link this principle to humanity's basic equality. Surely they are not arguing that all living things are equal and deserve equal treatment based on their having this divine spark that explains their being alive, only humans. However, if $\overline{o k r a}$ is what explains life generally, then either all living things must be equal, or merely having an $\overline{o k r a}$ does not make all humans equal.

Leaving this point aside, one is licensed to infer that personal identity is not a result of having an ōkra. One's identity could not be defined by what makes him/her equal to either all other humans or living things. Thus, we must think of $\bar{k} k r a$, as it relates to personal identity, as being a necessary but not sufficient condition for having an identity. As such, one's character and characteristics, which seems (at least on Schechtman's view) to be inextricably linked to personal identity, cannot be parts of $\overline{o k r a}$.

Gyekye diverges from Wiredu's interpretation of the essential nature of the $\overline{o k r a}$. He thinks that the Akan conception of the $\bar{k} k r a$ is closer to a traditional Western conception of the soul than does Wiredu. Gyekye shares Wiredu's interpretation of the ókra as a divine spark, and like Wiredu Gyekye argues that this divine spark makes all human beings equal to each other. However, on Gyekye's interpretation, the immaterial okra encompasses both the character (the sumsum) and the mind (the adwene) of the individual. When speaking about the relationship between the okra and the sumsum, Gyekye, perhaps with Leibniz in mind, tells us that "given $x$ and $y$, if whatever is asserted of $x$ can be asserted of $y$, then $x$ can be said to be identical with $y$. If there is at least one characteristic that $x$ has but $y$ does not, then $x$ and $y$ are not identical" (Gyekye 1998, 63). Gyekye goes on to tell us that the sumsum is not the okra, yet: "The sumsum may, more accurately, be characterized as a part-the active part-of the ökra (soul)" (Gyekye 1998, 63). The character traits and characteristics that make up personal identity are the active parts of the $\overline{o k r a}$, with the passive part of the $\overline{o k r a}$ perhaps being merely the potential to actualize certain traits, which he could then rely on to ground the basic equality of all persons (if he takes the $\bar{k} k r a$ to be what explains human life specifically). Gyekye links a human's personal identity to the okra by the sumsum's being a part of the okra. Gyekye tells us that: "Personality and character dispositions of a person are the function of the sumsum. The sumsum appears to be the source of dynamism of a person, the active part or force of the 
human psychological system..." (Gyekye 1998, 63). Gyekye is then able to conclude that one's individuality is both located in the $\overline{o k r a}$, and that individuality is not lost after death, insofar as the sumsum is within the okra, and the okra is immaterial and indestructible. ${ }^{2}$ As such, Gyekye's view of personal identity needs to go no further. Personal identity is given to the human when a divine being places his/her ōkra within him/her. For Gyekye: "The $\bar{o} k r a . .$. is the principle of life of a person and the embodiment and transmitter of his or her destiny" (Gyekye 1995, 97). Thus, whereas Wiredu endorses the communality of personhood, Gyekye rejects the notion of a socially determined and perhaps (though not necessarily) a narrative self, and could argue that the narrative is nothing more than the flowering out of the self as constructed before birth.

So, we are able to see the differences between Wiredu's and Gyekye's interpretations of the $\overline{k r a}$ in the Akan tradition. Now, while Gyekye is relatively silent as to the divisions of the honam (body), Wiredu introduces a particular aspect of the honam that may be beneficial to understanding the social nature of personal identity (as it relates to questions of characterization). Wiredu tells us that the body is thought to be composed of the mogya, or the human's blood. For the Akan, on Wiredu's interpretation, the mogya, in making up the physical blood of the human, is thought to be the matrilineal identity passed on to the human. Wiredu tells us that: "Since the Akans are matrilineal people, it is the kinship status that situates a person in the most visceral relationships and brings him into the most existential of the networks of obligations, rights, and privileges that characterize Akan communalism" (Wiredu 1997, 50). What Wiredu has in mind here is that the agent's mother's ancestral identity passes on to the agent, and society recognizes this identity when engaging the agent. The blood that the agent has will frame part of an agent's identity insofar as society will recognize him/her in a certain way because of his/her maternal lineage. What we can take from this is that a human has constraints placed on his/her identity even before he/she is born. Consider Wiredu again, when speaking not only of the mogya but also the sumsum:

Both the maternal and paternal contributions to the person are bases of membership in specific social units. Akans are matrilineal; therefore, the blood principle [Mogya] situates a person in the important kinship units, namely, the lineage or, more extensively, the clan. Through the charisma principle [Sumsum] one belongs to a grouping on the father's side that is largely ceremonial but also a framework for much goodwill. The point now is this: on Akan showing, a person [understood here as merely a human] has a well-structured social identity even before birth (Wiredu 1992b, 85).

For the Akan, identity has a social aspect to it that determines the type of identity each human will take, even before personhood is achieved. Your community will determine how you are able to construct your identity, insofar as it will set parameters

\footnotetext{
${ }^{2}$ Perhaps a better way to think of it is that the sumsum is the capacity of the okra to think, desire, feel, imagine, etc. It would not be two different entities, but one entity with a certain power that we give a different name to (potentially to differentiate the types of existing okra).
} 
within which identities can be constructed before your birth. These parameters situate you; they are necessary and sufficient conditions for the possibility of there being a "you." These will be parameters that you, no matter how much you rebel, will respond to and struggle with but never get outside of. You will use them to cultivate yourself and determine other human's identities by preserving or reworking them.

Here we are able to see features of identity that should not be overlooked, namely that we are born to certain people, and with certain features. Now, we as Westerners may not place very much stock on the idea that we have our identities transposed into us by our parents blood and semen. Still, I think that we can appreciate what the Akan suggest when we think consider that we do get particular proclivities and psychological traits such as predispositions to Alzheimer's, schizophrenia, mental acuities, etc. and biological makeups such as skin color, susceptibility to particular health conditions, etc. from our ancestry. These will in some sense determine the parameters of our identities, and though we may struggle with them, they of necessity participate in what we take to characterize ourselves. The person who has a history of schizophrenia in his/her family will form a particular conception of self, and a particular narrative in light of this history. He/she might set out to better understand schizophrenia by becoming a doctor, or may develop neurotic tendencies due to anxiety that he/she will be affected by schizophrenia. This history sets the parameters of this person's identity, and are woven through his/her narrative. How he/she responds to this history is to be explained by other social constraints and parameters operating around and within him/her.

Moreover, we cannot ignore that who we are born to, as well as what physical features we have, matter insofar as we will be recognized in our social communities for having these features. Our communities confer a type of value to our family names, medical conditions, and basic physical features in a manner that determines our identities. For example, W.E.B. Du Bois made the famous appeal to "double consciousness" as what principally informs black identity at the turn of the twentiethcentury (Du Bois 2003, 9). This identity-marker is only possible if one is socially recognized for having particular physical traits that have a particular value in community that does not depend on the individual or any "spontaneous" acts of the will. Our bodies matter insofar as they are given a particular value in society.

Thus, there seems to be a problem with Schechtman's thinking on personal identity. Schechtman argues that an answer to the characterization question requires the support of a psychological theory in which answers the reidentification question. Yet, it appears to be the case that she fails to appreciate how bodies affect psyches, and are affected by social value, such that societies determine how bodies are valued, which determines possible psychological characteristics and the potential ways in which these characteristics are developed-that is to say, which psychological characteristics a person can/will have. So, let us say that characteristics are psychological, and thus that the characterization question is answered only by being undergirded by a psychological continuity theory. However, it appears to be the case that one cannot explain psyches without appeal to bodies. We have certain psychological characteristics because of the types of bodies that we have. Now, it 
would appear that a part of the reason why bodies are able to influence our psyches is because they have a certain sort of value. The value that is placed on an individual's body affects the type of psyche that the individual has. Yet, we cannot explain the value of our bodies, as they relate to our psychological development, without appeal to our communities. Communities determine the value of our bodies, and this determination is responsible for the psychological states that characterize our personal identity. As a result, we cannot explain what characterizes an individual without the determination of the community in conferring a value to the bodies that determine the physical features that we have.

Who we are born to - the genes and bodies that we have-matter in determining who we are, and communities make bodies and genes meaningful insofar as they determine the value of these physical traits. This determination affects what identities we take. Thus, community is a necessary component in the determination of personal identity, insofar as it determines both the value of the bodies that we form narratives with, and the parameters of the narrative that make up individual identity. So, it would appear that our social communities, in being the sources of our biological makeups and giving value to our bodies and biological makeups, play a larger role than what must merely be synched with the individual narrative so that the individual can live the life of a person. If we take Wiredu seriously, we understand that the narratives that are our identities begin with our communities even before we are born, and that our communities value features beyond our control that will determine what characterizes us.

There is one final idea expressed by the Akan that I would like to discuss, and it is this idea that I believe best illustrates the social nature of personal identity, namely the Akan conception of personhood as an achievement. Now, it would be beneficial to begin by stating that much of the controversy surrounding the human/person distinction, along with the conception of what a human being is, regards language. Among the Akan, the word for both human and person is onipa (Wiredu 1992a, 104). One might suppose, as Gyekye does, that the Akan conceptualized the person and the human as being inseparable, and thus to speak of a human is to speak of a person, and vice versa (perhaps because of the divine spark) (Wiredu and Gyekye 1992). Still, like Wiredu, one might think that Gyekye fails to capture certain usages of the term that seem to add something to the ordinary conception. Considering Wiredu, who tells us the following story:

In 1979, President Kaunda of Zambia gave high praise to then Prime Minister of Britain, Mrs. Margaret Thatcher, for her unexpected constructiveness during the last series of negotiations that led to the termination of white minority rule in Zimbabwe. He said that she was 'truly a person,' and he immediately provided a key to this choice of words.... On this showing, the 'Iron Lady' received very high marks indeed. The semantics of personhood in the language of the Zambians is similar to the semantics of personhood accepted by the Akans of Ghana and the Ivory Coast (Wiredu 1992a, 104). 
President Kaunda's use of "person" seems to diverge from the ordinary usage insofar as it seems to add significance to Thatcher's humanity. Why point out that Thatcher is a human being when honoring her for some achievement? President Kaunda seems to use the term in an elevated sense, suggesting that Thatcher has achieved some level of excellence or has achieved something that needed to be publicly recognized. Thus, Wiredu concludes that for the Akan, personhood is something that a human being achieves through a certain type of action in community.

On Wiredu's account, personhood is achieved when an individual human being achieves certain notable successes and performs particular rights, social duties, and moral obligations that are relative to their individual starting-points. Wiredu tells us that: "In Akan thinking, as indeed in the thinking of many other African peoples, a person in the true sense is not just any human being, but one who has attained the status of a responsible member of society" (Wiredu 1997, 51). Further, Wiredu tells us that "personhood is not an automatic quality of the human individual; personhood is something to be achieved, and the higher the achievement, the higher the credit" (Wiredu 1992a, 104). So, in addition to personhood being something that humans strive towards, Wiredu thinks that for the Akan there are degrees of personhood such that an individual can achieve different levels of personhood. "In the path of improvement, there are, theoretically, endless vistas of higher personhood" (Wiredu 1997, 51). For Wiredu, personhood is a multileveled achievement, or a sort of honor conferred onto a human being for performing and upholding particular duties and moral obligations.

One potential problem with this view is that it may lead to inequalities in treatment of individuals, such that some members of the community may not be respected. And this may create an inequality in the distribution of goods that determines one's ability to flourish economically or in abilities to act morally, and thus in the possibilities of becoming persons. If this were the case, then the conception of personhood as an achievement would be a privileged term, insofar as one would have to begin in a privileged position to have the possibility of achieving personhood. Gyekye expresses a worry like this one. For Gyekye, the Akan are fundamentally committed to human rights, and as such they cannot conceptualize there being levels of personhood, insofar as their commitment to human rights could then be called into question (Wiredu and Gyekye 1992, 152).

In response to this type of objection Wiredu argues that the Akan commitment to human rights is still preserved insofar as the Akan conception of personhood as an achievement is open-ended, but only on one side. Wiredu thinks that there are levels of personhood that extend indefinitely. Still, he argues that one can never sink below the level of humanity. All humans are equal, insofar as all humans have an ōkra. In this way, all humans are entitled to respect as humans. Even still, one might be awarded a particular level of recognition in accordance with achievements and moral activity. We may better understand this difference by looking at Stephen Nathanson's division of types of desert. Nathonson tells us that there is personal desert, whereby someone deserves a certain type of treatment or level of respect because of what 
he/she has done. He contrasts personal desert with human desert, whereby someone deserves treatment or a level of respect irrespective of what he/she has done (Nathanson 2001, 139). With regard to Wiredu, one would deserve a basic level of human respect because of the $\overline{o k r a}$ (or the type of $\overline{o k r a}$ ) that was placed into them, and would deserve this respect irrespective of any achievements. However, once they have achieved a level of personhood, they would deserve a level of respect based on their actions in community.

Now, this may or may not solve the problem. One might still think that personhood, as conceived in this way, will affect how one is treated as a human being as well as one's ability to achieve personhood, making it easier for some than for others. Moreover, one might question the political nature of this process, such that heroic actions fail to be recognized, and thus some humans might not be accorded personhood status because of the political commitments of their communities. To offer a defense of the Akan, this critique points to the very political nature of human beings and human actions. The value of our actions will always be interpreted in the light of our communities' politics. Critiquing this notion of personhood and the treatment of humans on these grounds would not carry anymore weight than critiquing how we value particular figures in history because their views express our own political commitments. In any event, the Akan conception of personhood as an achievement can be useful insofar as it allows us to more clearly see the social nature of individual identity through its depiction of the ways in which social recognition has an effect on one's self-image, and can even show us that our ability to re-identify with our past actions is possible only through social community.

Wiredu's interpretation of the Akan conception of personhood allows us to see the impact that communities have on identity because it implicates the ways in which communities affect which narratives become important for us to have. What I mean here is that social recognition is what is most important to our self-images, and we will go to great lengths to obtain it. Crafting our identities (constructing our narratives) so as to be accepted socially is the primary way that we cultivate positive self-images. For the Akan, personhood is a type of social recognition that individuals strive for and are granted because of particular actions enacted and lives led in community. What we can take from this is that communities determine the value of individual actions and lives insofar as they grant this status that individuals desire as they pursue positive self-images. Because individuals strive to achieve social recognition, we can infer that individuals place a premium on being socially recognized when individuals carve out identities for themselves. An individual will not carve out an identity that is not intended to produce social recognition. It is wrong to think that we carve out identities so that we will be happy, irrespective of our communities. A community recognizing us in a certain sort of way is what makes us happy, and is the reason we are concerned to construct certain narratives. In fact, social recognition is the reason why we desire others to reconstruct (re-narrate) our lives in particular ways. In this way, we are able to see that social communities determine our identity insofar as we carve them out in order to achieve a recognition that can only be granted in community. This phenomenon does not merely regard the 
Akan; it is merely the case that the Akan conception of personhood helps us to see it more clearly.

It is easily noticed that for the Akan, personhood depends on social recognition; we may say that for the Akan, personhood as achievement is a type of social recognition. And because personhood depends on social recognition, one may infer that if personhood is important to an individual, then social recognition will be important to him/her. In fact personhood, as a type of recognition, cannot be unimportant to an individual because of his/her social nature. Even if personhood is not granted by those with the greatest amount of political power in the community, an agent seeks an "equivalent" type of recognition from a less powerful community. ${ }^{3}$

Now, if social recognition has the importance to the individual that I claim that it does, then the narrative that he/she attempts to carve out for him/herself will be for the purpose of receiving this social recognition, insofar as he/she attempts to incorporate socially accepted norms and values into the life that he/she lives. The reason for this, again, is that his/her positive self-image, in being inseparably linked to what others think or know about him/her, is linked to social recognition. Consider Wiredu when he writes about the link between social recognition, self-images, and identity: "Indeed, one of the most agonizing moments in the life of an Akan is being constrained to ask, 'Am I ever going to become a person?' This is a supreme moment of self-questioning that can, in some cases, have a transforming effect" (Wiredu 1992a, 108). Here we are able to see the intimate connection between one's selfimage and the achievement of personhood as a type of social recognition. And as such, we are able to see the intimate connection between identity and social recognition. Failing to receive social recognition in the form of the achievement of personhood can cause an existential crisis, and this allows us to see the impact that social recognition, as accorded to us by our communities, has on identity. Not only is the individual depicted here as having what we may term an "identity-crisis," which, for Schechtman, regards the fundamental issue of characterization, but we are able to see the desire for social recognition determining what identity the individual thinks he/she ought to have in a way that affects his/her self-image, and thus has a capacity to alter features that characterize the individual.

So, we are able to see the connection between narratives and social recognition. Now, if an individual's narrative is inseparably linked to social recognition, such that his/her narrative will be constructed in accordance with a desire to be recognized in a certain sort of way by his/her community, then it seems that we are licensed to infer that the individual's community determines his/her narrative. More than simply synching up with his/her narrative, and perhaps even more than simply determining the parameters of the narrative (as has been demonstrated above with the use of the components of the Akan conception of the human being), his/her community defines

\footnotetext{
${ }^{3}$ This explains people's attempts to construct narrative identities against particular mainstream political values, leading them to become members of cliques, gangs, and terrorist groups. Thus, ultimately I am not arguing that there is a static type of social recognition conferred by a political community. As will become clear, there are different sub-communities within a larger political community that confer social recognition.
} 
the type of narrative that he/she desires to have, and ultimately will construct because of his/her desire for recognition. In fact, it would appear that his/her community is itself responsible for him/her having a desire to for characteristics that form an identity.

One may question how it is possible to ask such an existentially probing question if communities determining identity. In other words, how can this existential crisis be the result of not achieving social recognition when the desire to achieve social recognition is determining the type of narrative that I construct, and thus the type of identity-characteristics that I have? How can the individual having the existential crisis be affected by an identity that he/she ought to have, but does not have, if social recognition determines the identity that he/she does have? My answer is that, when looking at Wiredu's statement, it would appear that he is simply taking the dominant political community to be that in which confers this social recognition onto an individual. We may understand the existential (identity) crisis as a realization by the individual having the crisis that he/she has failed to accept the values of the dominant political community when constructing his/her narrative, and not that his/her identity was not constructed so as to achieve social recognition from any community whatsoever. The existential crisis is the result of realizing that the "wrong" community has determined who the individual is (what characterizes the individual).

Thus, my argument here is not that the dominant political community, or even one community completely determines individual identity. One may think of the relationship between the individual and his/her social community as it relates to identity as a push/pull relationship, and the relationship between communities as it relates to the identity of individuals in the same light. There is social influence on identity from the very beginning, insofar as one's community determines the parameters of individual identity prior to his/her birth. As the individual grows, he/she might accept those parameters and attempt to work towards the social recognition of that community - he/she might construct a narrative in line with the values that his/her community has setup for him/her. The individual might also reject either parts or the whole of the community's values, seeking recognition from another community. However, at no time is a community not in some sense pressing on the individual in his/her narrative-construction. And at no time is the individual's identity not being defined by a community's recognition that he/she desires for a positive selfimage. Communities are crafting the individual as the individual is crafting him/herself to the liking of a community.

Let's look at an example of this. Say we have person A (call him Joseph) and Person B (call him Jack). Both Joseph and Jack were born in a highly conservative (define it however you wish) community (Community ${ }_{1}$ ) and thus have had the parameters of their individual identities defined for them prior to birth. Joseph accepts his social community and thus attempts to be recognized by his community. In the Akan sense, Joseph seeks personhood within this community. Jack, on the other hand, rejects the conservative community $\left(\right.$ Community $_{1}$ ) and begins to construct his identity around a liberal community (Community 2 ). Looking at Jack's narrative, it would not be right to think that because Jack rejects Community ${ }_{1}$, a community is not 
determining his identity. It would be right to think that Community ${ }_{1}$ and Community 2 are determining Jack's narrative even after Jack rejects Community. Jack is responding to (rejecting) his conservative community, which means that Jack is not simply a leaf blown in the wind insofar as the social nature of his individual identity is concerned. There is a push/pull relationship, and thus we might think that there is some "freedom" in his attempt to construct his identity. Still, it would be wrong to think that the conservative community does not determine Jack's identity even after he rejects it. In his rejection, he consciously attempts to act so as not to embrace the values of Community ${ }_{1}$, which evidences its determination on him. ${ }^{4}$ Further, as is evident, it would be wrong to think that no social community is determining Jack's identity after he rejects his conservative social community. He seeks recognition from a liberal community. And thus, his identity is at each moment being determined by these communities in his attempts to both distance himself from, and be recognized by, a community.

Now, it is not merely the case that social communities define individuals without individuals being able to redefine the content of the parameters that will shape others within these communities. Recall that individuals' identity is socially determined from the very beginning of individuals' lives, which is to say that communities determine the parameters of individuals' identities prior to their births. Recall also that some individuals will accept their communities' values. Others from these communities will reject certain of their communal values, so long as there are no absolute constraints on the individual. What I am suggesting here is that the rejection of a community's values is contingent on there being access to different values and/or models of social life. If there is access to different values or models of social life, and individuals reject their communities' values, then these persons are able to rethink the values that do and will define other individuals. The rejection of the communal values is a response to individuals' exposure to different values and either individuals being rejected from certain of the communities' social practices/benefits or individuals' recognition that the values of the community are deficient in some way.

Let us see an example of this. Recall our example of the conservatism of Jack and Joseph. Recall that Jack rejected his conservative community (Community ${ }_{1}$ ) in favor of a liberal community (Community ${ }_{2}$ ). Recall also that both communities are in some

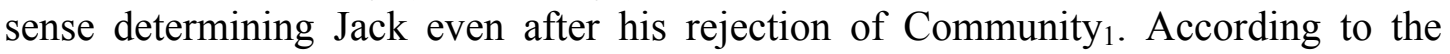
argument that I have just set forth, Jack will have needed to be exposed to a separate set of values (those embraced by Community ${ }_{2}$ ) and either will have been rejected from certain of the communities social practices/benefits or will have recognized a deficiency of particular values held by those within Community. Perhaps Jack was led to reject Community ${ }_{1}$ because he is of a particular race that was excluded from access to certain social goods because of his race, or perhaps he had a particular sexual orientation around which oppressive values were constructed. Jack may have

\footnotetext{
${ }^{4}$ One can perhaps think of the transgendered person who no longer identifies as male. In the very statement, "I no longer (do not) identify as male," masculinity is still informing her identity because it is certain that her actions are consciously made so as not to be masculine.
} 
recognized certain sexist values within the community even if he was not a member of the sex who was harmed by those values. After having been exposed to Community,'s values and having rejected Community,'s values, Jack might attempt to influence the parameters set by Community ${ }_{1}$ by attempting to infuse more of Community,'s values into Community ${ }_{1}$. He may feel obligated to do so from a perceived duty to his family or posterity, or perhaps he is driven by patriotism or thoughts that many of the values of the community ought to be preserved. In this way, he might attempt to preserve conservative values that are taken to be adequate and reform other conservative values that are taken to be oppressive.

\section{CONCLUSION}

What I present here is neither a complete endorsement of the Akan conception of personhood as an achievement that is given to us by Wiredu nor the general notion of humanity that is presented by either Wiredu or Gyekye. There are many reasons to worry about these conceptions. Personally, I take them to be very rich conceptions that I do not share. However, this is not to suggest that there is nothing in Western cultures that do not liken to the Akan conceptions, particularly personhood as an achievement. Terms such as "real woman" (to distinguish a female achieving moral and social maturity as opposed to an immature adult female) are used in many African American communities and sang about by artists like Mary J. Blige. Conceptions like "real woman" seem to be comparable to the Akan conception of personhood. Moreover, I do think that by viewing them, we can begin to understand the deeply social nature of individual identity. To answer the question, "who am I" is to have a narrative, and to have a narrative not only involves a social community in my engagements, but involves a social community determining the value of those engagements, recognizing me in a certain way for those engagements, and providing the descriptive and normative grounds for my future projects while giving me every possible project to which I aspire.

\section{ACKNOWLEDGEMENTS}

I would like to thank both Shaun Gallagher and Deborah Tollefsen for their helpful comments on this paper. Thanks also to the following individuals for their feedback and helpful suggestions: Benjamin Aguda; Josh Dohmen; Daniel Larkin; Sarah K. Marshall; John Torrey; Sarah Vincent; Stefano Vincini. Finally, I would like to thank the anonymous reviewers of Comparative Philosophy for their thought-provoking comments on various drafts of this paper. 


\section{REFERENCES}

Aristotle (1957), On the Soul, in W.S. Hett (trans.) Aristotle: On the Soul, Parva Naturalia, On Breath (Cambridge: Harvard University Press).

Du Bois, William Edward Burghardt (2003), The Souls of Black Folk (New York: Barnes and Noble Classics).

Gyekye, Kwame (1995), An Essay on African Philosophical Thought: The Akan Conceptual Scheme (Philadelphia: Temple University Press).

- (1998), "The Relation of Ōkra (Soul) and Honam (Body): An Akan Conception", in Emmanuel Chuckwudi Eze (ed.) African Philosophy: An Anthology (Malden: Blackwell Publishers Inc.), 59-66.

Nathanson, Stephen (2001), An Eye for an Eye: The Immorality of Punishing by Death (Lanham: Rowman \& Littlefield Publishers, Inc.).

Schechtman, Marya (1996), The Constitution of Selves (Ithaca: Cornell University Press).

Wiredu, Kwasi (1992a), "The African Concept of Personhood", in Harley E. Flack and Edmund D. Pellegrino (eds.) African-American Perspectives on Biomedical Ethics (Washington, DC: Georgetown University Press), 104-117.

- (1992b) "The Moral Foundation of African Culture", in Harley E. Flack and Edmund D. Pellegrino (eds.) African-American Perspectives on Biomedical Ethics (Washington, DC: Georgetown University Press), 80-93.

- (1997), "African Philosophical Tradition: A Case Study of the Akan", in John P. Pitman (ed.) African-American Perspectives and Philosophical Traditions (New York: Routledge), 35-62.

Wiredu, Kwasi and Kwame Gyekye (1992), Person and Community: Ghanaian Philosophical Studies (Washington, D.C.: The Council for Research in Values and Philosophy). 